\title{
The monster of Udine
}

\section{Il mostro di Udine}

\section{El monstruo de Udine}

\author{
Linda Pontoni \\ Dottoressa Magistrale in Investigazione, Criminalità e Sicurezza Internazionale, Università degli Studi Internazionali di \\ Roma (UNINT), Italy
}

\begin{abstract}
In this paper, I have examined a still unsolved case that involved the small town of Udine between 1971 and 1989. Forteen the crimes committed by the Monster of Udine as he has been defined, whose identity remains unknown even today. Attention will be focused on the victims of the murders, characteristics in common and not, of the different crime scenes, the discovery of the objects and on the "signature" left on the various bodies. Subsequently, the focus will be on the different criminological profiles of serial killers, starting with the official classification of the FBI, and then inserting the one updated by professors V. Mastronardi and G. Palermo. Since this is still an unsolved case and therefore without a culprit, we will proceed according to an exclusion process, starting from the observation also of the "modus operandi" used and then analyzing the behavior that the offender has put in place, up to trying to draw a profile. In the last chapter, moreover, the elaboration will highlight the most recent aspect of the story, relating to the last reopening of the investigations, which took place in 2019, thanks to the discovery of new material, including the various interviews made to those who contributed to the case of the Monster of Udine.
\end{abstract}

\section{RIASSUNTO}

In questo mio elaborato, ho preso in esame un caso ancora irrisolto che ha coinvolto la piccola cittadina di Udine tra il 1971 e il 1989. Quattordici i crimini avvenuti da parte del Mostro di Udine così come è stato definito, di cui ancora oggi ne rimane sconosciuta l'identità. Verrà mirato il focus attentivo sulle vittime degli omicidi, caratteristiche in comune e non, delle diverse scene del crimine, sul ritrovamento degli oggetti e sulla "firma" lasciata sui vari corpi. Successivamente, ci si concentrerà sui diversi profili criminologici dei serial killer, iniziando dalla classificazione ufficiale dell'FBI, per poi inserire quella aggiornata dai professori V. Mastronardi e G. Palermo. Trattandosi di un caso ancora oggi irrisolto e quindi senza un colpevole, si procederà secondo un processo di esclusione partendo quindi dall'osservazione anche del 'modus operandi' utilizzato e quindi analizzando il comportamento che l'autore dei reati ha messo in atto, fino a tentare di tracciarne un profilo. Nell'ultimo capitolo, inoltre, l'elaborato evidenzierà l'aspetto più recente della vicenda, relativo all'ultima riapertura delle indagini, avvenuta nell'anno 2019, grazie al ritrovamento di nuovo materiale, ivi incluse, le varie interviste fatte a coloro che hanno contribuito al caso del Mostro di Udine.

\section{RESUMEN}

En este artículo, he examinado un caso que involucró a la pequeña ciudad de Udine entre 1971 y 1989. Un caso que sigue sin resolver. Catorce los crímenes que tuvieron lugar por el Monstruo de Udine tal como ha sido definido, cuya identidad sigue siendo desconocida incluso hoy en día.La atención se centrará en las víctimas de los asesinatos, características en común y no, de las diferentes escenas del crimen, en el descubrimiento de los objetos y en la "firma" dejada en los distintos cuerpos. A continuación, nos centraremos en los diferentes perfiles criminológicos de los asesinos en serie, comenzando por la clasificación oficial del FBI, y luego insertar la actualizada por los profesores V. Mastronardi y G. Palermo. Dado que se trata de un caso aún sin resolver y, por tanto, sin un culpable, se procederá según un proceso de exclusión partiendo de la observación también del modus operandi utilizado y luego analizando la conducta del delincuente, hasta tratar de hacer un perfil. En el último capítulo, además, el trabajo pondrá de relieve el aspecto más reciente de la cuestión, relativo a la última reapertura de las investigaciones, que tuvo lugar en el año 2019, gracias al descubrimiento de nuevo material, incluidas las diversas entrevistas realizadas a quienes contribuyeron al caso del Monstruo de Udine.

\section{Il mostro di Udine}

Per luogo comune, quando viene utilizzato il termine "mostro", la mente riporta all'autore di otto duplici omicidi avvenuti tra il 1974 e il 1985, nella provincia di Firenze. Analogamente, l'organizzazione terroristica delle Brigate Rosse iniziava a propagandare la lotta armata ricorrendo a sequestri di persona, violenze e uccisioni. Tutta l'attenzione dei media italiani era rivolta a questi fenomeni, che hanno portato un clima di paura e di tensione comune, lo stesso che ha fatto sì che nessuno di accorgesse di ciò che stava contemporaneamente accadendo all'estremo nord-est della nazione.

Udine, uno dei capoluoghi di regione del Friuli-Venezia Giulia, è stata teatro di alcune delle morti più spaventose ma allo stesso tempo meno conosciute della storia italiana, messe in atto da colui che venne poi soprannominato il "Mostro di Udine", o "Killer della pioggia". Una sorta di imitazione del più famoso serial killer inglese, Jack lo Squartatore, dal quale copiava modus operandi e l'odio che lo spingeva a compiere tali gesta. 
Il Mostro di Udine è stato l'autore di 14 omicidi di donne, messi in atto fra il 1971 e il 1989, tutti rimasti irrisolti. Le vittime erano quasi tutte prostitute. La stampa lo aveva rinominato come il "Serial Killer della pioggia", perché agiva sempre allo stesso modo, in angoli e periferie poco illuminate, durante il fine settimana, in condizioni di maltempo.

Le dinamiche sono molto simili a quelle del Mostro di Firenze, anche se non aveva scatenato lo stesso interesse mediatico, ma aveva scatenato una grande paura in tutta la regione, costringendo i cittadini a chiudersi in casa, con porte e finestre sbarrate. Recarsi al lavoro o al ristorante era diventato un vero e proprio pericolo, dettato anche dal fatto che questo serial killer non aveva una faccia, poteva nascondersi nel vicino di casa, in colui che passeggiava dietro di noi; poteva essere chiunque.

Dopo più di 30 anni, le cose non sono cambiate. I 14 omicidi rimangono ancora irrisolti, e il colpevole sconosciuto. C'è stato un sospettato del quale non hanno mai divulgato il nome, ma soltanto un identikit. Un uomo trovato in stato confusionale sull'ultima scena del delitto, quella di Marina Lepre, ma sul quale non si è mai riusciti a trovare delle prove.

La stessa notte dell'omicidio, poche ore dopo il ritrovamento del corpo, due carabinieri si trovavano sul luogo del delitto per effettuare un sopraluogo. Mentre ispezionavano la zona, udirono dei lamenti. Si trovarono davanti ad un uomo, di età apparente sui 60 anni, che invocava perdono davanti all'entrata di una chiesa, con le braccia protese al cielo. Dai documenti dell'uomo, emerse che si trattava di un medico specializzato in ginecologia. Lo riaccompagnarono a casa, dove risiedeva insieme al fratello. Arrivati sul posto, sarà proprio il fratello a negare l'accesso ai carabinieri, in quanto sprovvisti di mandato di perquisizione.

Il tutto rimase in sospeso fino al 1996, quando riaprirono le indagini nei confronti di questo individuo, ed emersero importanti disturbi mentali, che avevano impedito al medico di esercitare la sua professione. Venne anche perquisita la sua abitazione, ma senza alcun risultato. Non vennero infatti ritrovati elementi decisivi o utili alle indagini. Il sospettato morì poi nel dicembre 2006, e con lui l'inchiesta a suo carico.

\section{Gli omicidi}

\section{1 settembre 1971, piove}

Irene Belletti, la prima vittima del serial killer della pioggia. Questo omicidio, all'epoca, ha sconvolto l'interna cittadina udinese. 35 anni, originaria di Trevi, in provincia di Perugia, si era da tempo trasferita in una zona residenziale della città friulana assieme al figlio tredicenne. Lavorava come prostituta non molto distante dalla stazione ferroviaria, in quella che un tempo era considerata la periferia sud di Udine.

Era da poco passata la mezzanotte, quando la redazione di un quotidiano locale riceve una telefonata con cui si segnalava il corpo senza vita di una donna nel Viale delle Ferriere. Il corpo viene ritrovato mutilato e gravemente straziato all'interno di un'auto vicino alla stazione dei treni di Udine. A trovare la donna senza vita non sono state le forze dell'ordine o i giornalisti, ma Fulvia Candotti, anch'essa prostituta e amica della vittima, che l'ha riconosciuta mentre camminava nel Viale. Il corpo senza vita giaceva sul sedile del passeggero illuminato dalle luci interne dell'auto, una Lancia Fulvia, rimaste accese dopo l'omicidio.

La morte è stata causata da un'arma da taglio, con cui le sono state inflitte sette coltellate in tutto il corpo, principalmente localizzate nella zona dello sterno, schiena e nella parte posteriore del collo. L'ipotesi era quella che la vittima fosse protratta verso il suo assassino, che ha poi iniziato a colpirla nella parte alta del dorso. La pista della rapina venne scartata subito, in quanto all'interno dell'auto venne rinvenuta la borsetta della vittima e tutto il suo contenuto. Il presunto autore del delitto venne ricercato fra prostitute, vagabondi, protettori, ma non si arrivò mai a una conclusione. La voce anonima e l'assassino rimasero senza nome.

L'ipotesi iniziale era quella che si fosse appartata con il compagno alla ricerca di un po' di intimità, e per questo il primo rimando, proprio in relazione al modus operandi, fu al Mostro di Firenze. L'auto della vittima rivelava numerose impronte digitali, forse anche quelle dell'assassino, che avrebbero potuto riportare il suo DNA. All'epoca però le tecniche investigative non erano sviluppate come lo sono invece oggi, e le impronte venivano prese con della carta assorbente. Per la prima volta, gli inquirenti si sono inconsapevolmente trovati davanti all'operato del Mostro di Udine.

Oggi, come allora, si definisce una vittima "presunta" del serial killer, nonostante alcune analogie con i casi successivi.

\section{6 novembre 1972}

\section{Elsa Moruzzi}

52 anni. Il suo cadavere viene ritrovato all'interno di un appartamento nel centro della città. Si è parlato di evidenti segni di strangolamento e di cranio sfondato. Visto il diverso modus operandi, il caso non venne associato al precedente. Le indagini non portarono a nessun risultato.

\section{2 dicembre 1975}

\section{Eugenia Tilling}

Il suo cadavere venne ritrovato all'interno della sua abitazione, luogo dove era solita accogliere i clienti. In posizione prona, il letto ricoperto di sangue, con il collo trafitto da pugnalate mortali. Il fatto passò quasi inosservato come un "normale" fatto di cronaca nera.

Venne arrestato Walter Lizzi, un cliente abituale della vittima, che all'epoca aveva 25 anni. Prelevato dal suo luogo di lavoro, confessò immediatamente giustificando quanto accaduto perché in preda ad un raptus scatenato da delle battute fatte da Eugenia Tilling in merito alla sua impotenza.

Scontò 16 anni di carcere, durante i quali però ritrattò la sua colpevolezza dichiarandosi innocente. Aveva confessato il falso perché minacciato e picchiato dalle forze dell'ordine.

\section{0 settembre 1976}

\section{Maria Luisa Bernardo}

Ragazza di 26 anni. Nata a Cividale, era la più grande di 6 fratelli. Da tempo residente a Udine, viveva con il marito con una grave malattia renale e quindi bisognoso di cure, e due figli. A causa delle difficoltà economiche che stava attraversando la sua famiglia, la ragazza aveva deciso di dedicarsi alla prostituzione. $\mathrm{Si}$ concentrava in una zona non molto lontana dalla stazione ferroviaria di Udine, e vicino al luogo dove solo cinque anni prima era stato rinvenuto il cadavere di Irene Belletti. Il cadavere viene ritrovato abbandonato in un campo di grano a Moruzzo (Udine), colpito da 22 coltellate. I numerosi tagli alle mani e alle braccia dimostravano che la vittima aveva cercato di difendersi dal suo aggressore. Modus operandi e circostanze che, per la prima volta, hanno portato gli investigatori a ipotizzare un possibile collegamento con l'omicidio di Irene Belletti. 


\section{9 settembre 1979}

\section{Jacqueline Brechbuhler}

46 anni, nata in Francia, si era sposata a Udine alla fine degli anni ' 60 . Non era del tutto indipendente economicamente, così occasionalmente ricorreva alla prostituzione. Il suo cadavere viene rinvenuto a Colugna (Udine), martoriato da dieci coltellate.

\section{9 febbraio 1980}

\section{Maria Carla Bellone}

19 anni, fa la prostituta. Il corpo viene ritrovato il 19 febbraio, ma la data di morte presunta è il 16 febbraio. Conosciuta alle forze dell'ordine per i suoi problemi di droga, la sua non era stata un'infanzia facile, i genitori litigavano molto spesso; lei e suo fratello minore Dario avevano trovato una seconda vita nell'eroina. A 16 anni era stata fermata per spaccio di droga.

La sorella minore della vittima, Barbara Bellone, nel 1980 si reca alla stazione di Udine e prende il primo treno per scappare e mettersi in salvo, convinta che sarebbe stata la vittima successiva del Mostro. È da precisare che in quegli anni quasi tutti i giovani di buona famiglia prendevano la strada dello spaccio e della tossicodipendenza.L'ultimo avvistamento della donna risale verso le 3/3.15 circa di mattina in via Leopardi, mentre saliva su una Mercedes di colore chiaro.

Il suo cadavere viene rinvenuto in posizione supina, durante una serata piovosa, in una campagna di Pradamano (Udine). Il corpo era stato trascinato; attorno ad esso c'erano i suoi calzini e altri oggetti sparsi. Era stata sgozzata e successivamente pugnalata. Non c'erano segni di legatura. Gli esami tossicologici effettuati sul corpo della vittima risultano negativi. Dal momento che i rimasugli di eroina rimangono rilevabili per 6 giorni circa, si può affermare con certezza che al momento della sua morte la Bellone non fosse sotto effetto di sostanze stupefacenti. A poca distanza dal corpo vengono ritrovati tutti i suoi oggetti personali, con uno spinello che però risultò inutile, in quanto gli strumenti di allora non erano sviluppati come invece sono al giorno d'oggi, e il DNA all'epoca era ancora quasi del tutto sconosciuto nel mondo scientifico. Lo spinello è stato così archiviato nel fascicolo della Procura.

Rappresenta il primo vero importante omicidio nella storia del Mostro di Udine, rimanendo la prima delle quattro vittime sicuramente riconducili allo stesso autore. È proprio sul corpo della giovane ragazza, che l'assassino decide di lasciare la sua firma: un taglio dalla precisione chirurgica, a forma di "S", che dallo stomaco scende fino al pube, evitando accuratamente l'ombelico. Questo taglio rimanda alla tecnica che veniva utilizzata all'epoca per la realizzazione dei parti cesarei. Presentava altre due ferite da taglio nella zona anteriore del collo.

\section{9 marzo 1980}

\section{Wilma Ghin}

18 anni, di Marano Lagunare. Si tratta della vittima più giovane del Mostro di Udine, e non faceva la prostituta. È stata vista per l'ultima volta mentre usciva da un locale a Mereto di Capitolo. Ad un'amica, qualche sera prima di morire, aveva dichiarato la sua intenzione a trasferirsi a Milano per intraprendere la carriera da modella.

Il suo cadavere viene ritrovato carbonizzato nella discarica di Gradisca d'Isonzo. Nell'immediato viene accusato del delitto un giovane pugliese, ma, per mancanza di sufficienza di prove, tutte le accuse a suo carico vengono sciolte, e anche questo si aggiunge alla lunga lista di casi irrisolti.
Parliamo comunque di vittima presunta del Mostro di Udine, in quanto non presentava la firma dell'assassino e il modus operandi non era solito del serial killer della pioggia.

\section{4 gennaio 1983}

\section{Luana Giamporcaro}

22 anni, prostituta. Scappata di casa, spesso era stata sorpresa a dormire in stazione a Udine. Viene ritrovata sgozzata, in un campo di mais della periferia di Udine. Senza vestiti, al momento del ritrovamento indossava soltanto un foulard attorno al collo, anche piuttosto stretto, e degli stivali ricoperti di sangue. Sul suo corpo, come in quello di Maria Carla Bellone, è presente un lungo taglio a forma di "S" che parte dallo stomaco fino ad arrivare al pube, evitando l'ombelico.

Secondo gli investigatori e l'anatomopatologo Carlo Moreschi, che ha effettuato la perizia sul corpo della vittima, si tratta di un rituale ben preciso, con lesioni al collo e al ventre, che per forza deve essere stato effettuato dalla stessa persona. Per la prima volta, guardando la precisione del taglio sulla vittima, si è pensato che l'assassino potesse essere un medico.

Il cadavere era supino e i polsi erano stati legati dietro al corpo con la borsetta, quando la donna aveva ormai perso i sensi o post mortem. La criminologa Cinzia Gimelli ha dato a questo gesto simbolico un significato molto particolare; l'assassino ha immobilizzato la vittima affinché non potesse più fare del male neanche dopo morta ${ }^{1}$.

Successivamente al ritrovamento della donna, una prostituta decise spontaneamente di testimoniare, facendo presente che un suo cliente, un anestesista di Padova, si eccitava quando le sue pazienti perdevano i sensi, sembrando quasi morte.

\section{0 maggio 1984}

\section{Maria Bucovaz}

44 anni, sposata e madre di 4 figli. A seguito di difficoltà familiari e del suo lavoro da prostituta, si separa dal marito. Veniva descritta come una donna emarginata dalla società e senza amici.

Le viene concesso un appartamento delle case popolari della città, da cui viene poi sfrattata assieme al suo nuovo compagno convivente.

Insieme, si trasferiscono in una casa precaria a Cividale del Friuli (Udine). Viste le circostanze, continua a mantenere un ottimo rapporto con l'ex marito, a cui vengono però affidati i quattro minori, perché la donna riversava in gravi condizioni economiche.

Secondo le testimonianze, la sera della sua uccisione, Maria Bucovaz stava rientrando a casa con un taxi, come era solita fare, quando avrebbe poi incontrato quello che pensava essere un suo cliente, con cui si sarebbe appartata in un boschetto di Moimacco (Udine).

A scoprire il suo cadavere, all'alba, nel bosco, è stato un ricercatore di lumache che aveva approfittato della giornata piovosa.

La morte è avvenuta per strangolamento. Fa parte delle vittime presunte, perché sul suo corpo non è stata rinvenuta nessuna traccia della firma del serial killer.

1 Lena M, Agostini F (2019), Documentario Il Mostro di Udine. Ascent Film s.r.1. 


\section{3 agosto 1984}

\section{Matilde Zanette Bazzo}

44 anni, originaria di San Fior di Treviso. Il corpo è stato ritrovato in un campo di grano, da un automobilista che si era fermato ad urinare. Divorato dai topi, semi svestito, in una posizione che avrebbe facilmente portato ad una sola conclusione, se non fosse che il luogo in cui riversava era scomodo per la consumazione di un rapporto sessuale. Era morta da circa un mese.

Grazie alle testimonianze di alcune prostitute, che hanno fornito un modello di auto e un numero di targa ben preciso, questa volta le indagini hanno preso una piega diversa rispetto ai casi precedenti; dopo quasi una ventina di giorni, è stato arrestato Gianluigi Sebastianis, un giovane di 27 anni che faceva il falegname a Fagagna (Udine). In passato il ragazzo era già stato denunciato da delle prostitute perché solito a comportamenti deliranti e aggressivi. Davanti ad un rifiuto, l'uomo aveva più volte cercato di afferrare la gola delle donne, inveendo contro il genere femminile.

Accompagnato sul luogo del ritrovamento del cadavere ha subito dichiarato la sua colpevolezza, sottolineando dei particolari riguardanti la scena del crimine di cui, apparentemente, solo l'assassino ne sarebbe stato a conoscenza. Non passò molto tempo che il giovane ritrattò, confermandosi innocente, spinto a confessare dalle promesse fatte dal magistrato all'epoca.

\section{9 dicembre 1984}

\section{Stojanka Jokimovic}

Proveniente dalla Jugoslavia, viveva a Udine ormai dal 1975 assieme al figlio di 8 anni. Era da tutti soprannominata "Sonia". Il corpo venne ritrovato accanto alla discarica di San Gottardo (Udine); fu strangolata, probabilmente con una calza di nylon, che non è stata mai ritrovata. Dall'autopsia del medico legale, sono risultati molti segni superficiali causati da un'arma da taglio su più parti del corpo della vittima. Non si sa se il serial killer non avesse voluto infierire oltre sul corpo ormai senza vita, o se, disturbato da una macchina di passaggio, abbia deciso di ritirarsi prima di essere colto in flagrante.

Il suo cadavere venne trascinato per un braccio e infine ricoperto dalla pelliccia che indossava quella sera la donna; nessuna traccia dei suoi indumenti intimi.

\section{3 marzo 1985}

\section{Aurelia Januschewitz}

Prostituta di origini francesi, di 42 anni. I suoi genitori morirono quando lei aveva solo due anni, così rientrò in Italia e venne inserita in un orfanotrofio. Qualche anno più tardi il prete decise di rinchiuderla nel manicomio di Udine, in quanto la sua condotta sessuale dava scandalo. All'età di 19 anni le venne diagnosticata una gracilità mentale immorale; malattia che si portò dietro per tutta la vita e che la costringeva a visite periodiche presso il Centro Psichiatrico di Udine. Dal 1963 al 1969, venne ricoverata altre sette volte.

È però doveroso contestualizzare la situazione, in quanto in quegli anni le donne venivano ritenute di "serie B", e quindi sfruttate da tutti i compaesani. Era sufficiente un solo rifiuto, o una sola presa di posizione, per attribuire loro una malattia mentale.

All'interno delle strutture, alle bambine venivano rimboccate le coperte molto strette attorno alle braccia affinché non si toccassero; se venivano sorprese a farlo, venivano punite con colpendo gli incisivi con dei mazzi di chiavi. Se agitate, gli veniva messa la camicia di forza, o venivano immerse nude in delle vasche piene di ghiaccio. $^{2}$
Una sua collega la definì una donna estremamente paurosa, che si prostituiva sotto l'obbligo del marito.

L'ultimo avvistamento è stato verso le 22.30, quando alcuni testimoni la vedono uscire dal bar Lux visibilmente ubriaca e salire su una macchina, forse di un suo cliente. Il cadavere viene ritrovato in una strada bianca, nella periferia della città, nei paraggi della Fiera di Udine, completamente nudo e immerso nel fango. Il corpo giaceva appoggiato sul fianco destro. Gli arti superiori erano legati dietro alla schiena con un foulard. Sull'addome, tre tagli eseguiti in maniera impeccabile, senza alcun tentennamento. Secondo il medico legale effettuati con un elettrobisturi o una lama arroventata, unici due strumenti che permettevano alla ferita di cauterizzare, ovvero di fare richiudere i margini del taglio al fine di evitare il sanguinamento.

Indossava soltanto una calza e uno stivale; l'altro stivale e l'altra calza sono stati rinvenuti poco distanti dal corpo, accanto a una parrucca. Nel collo numerose le ferite da taglio.

\section{5 febbraio 1989}

\section{Marina Lepre}

L'omicidio più importante del Mostro di Udine, con lei nasce anche l'idea che dietro a un innumerevole serie di omicidi, ci possa essere una sola mano.

Aveva da poco compiuto 40 anni, originaria di Comeglians, si era trasferita a Cividale del Friuli insieme alla figlia Fedra Peruch di 9 anni. Sposata con un ingegnere, hanno divorziato a causa del lavoro di lui che lo portava troppo spesso all'estero. Di origini borghesi, dopo la laurea magistrale aveva trovato lavoro come maestra in una scuola primaria.

Non si prostituiva, ma soffriva di depressione, motivo per cui era caduta nel circolo vizioso dell'alcolismo.

La notte del 25 febbraio, prima di incontrare il suo assassino, aveva esagerato con l'alcool ed era finita in pronto soccorso per una ferita sul mento, causata da una rissa fuori dall'Hotel Ramandolo, in via Forni di Sotto 28. Aveva poi raggiunto un altro locale in cui aveva chiesto da bere, già visibilmente ubriaca, portando con sé due sacchetti di plastica contenenti del pane. Era stata invitata dal titolare a lasciare il bar in seguito a degli importuni fatti nei confronti di due militari seduti a giocare a carte qualche tavolino poco distante dal suo. Saranno gli stessi militari, una volta interrogati, a riportare una frase pronunciata dalla donna prima di uscire: "Lo sai che quando esco da qui mi ammazzano?"3

Alcuni testimoni la vedono camminare per un tratto di strada sotto la pioggia, per poi salire su una vettura Fiat di colore scuro, dopodiché vengono perse le sue tracce, fino al mattino successivo.

Il corpo è stato ritrovato sul greto del torrente Torre, nella periferia della città, da un uomo che faceva footing. Giaceva a terra ricoperta da spazzatura, poggiata sul lato sinistro. Fu proprio grazie a quel cerotto sul mento, che i medici riuscirono a dare subito un nome al cadavere abbandonato. Sgozzata con un'arma appuntita, anche su di lei l'assassino aveva deciso di lasciare la sua firma, un taglio molto preciso a "S" dal ventre fino al pube, evitando l'ombelico. Un solo taglio sul lato anteriore del collo.

Le ricerche durarono tutta la giornata del 26 febbraio, ma la stessa sera fu il carabiniere Edi Sanson, insieme al suo collega, a voler tornare sul luogo del delitto per assicurarsi di non aver tralasciato delle prove importanti.

2 Lena M, Agostini F (2019), Documentario Il Mostro di Udine. Ascent Film s.r.1

3 Ivi. 


\section{4 settembre 1991}

\section{Nicla Perabò}

47 anni, trovata strangolata all'interno della sua macchina. Il corpo è stato poi nascosto sottoterra. Non era una prostituta e conosceva molto bene il suo assassino.

Per questo omicidio venne arrestato nel 1993 Bruno Leita, e condannato a 17 anni di carcere. L'ex poliziotto Codromaz, all'epoca in servizio, si recò a casa dell'uomo che davanti a una bottiglia di vino confessò l'omicidio della donna. Secondo l'ex poliziotto, la confessione è avvenuta soltanto per il clima amichevole che si era creato, specialmente grazie al vino. Bruno Leita raccontò i fatti dicendo di averla soffocata in preda ad un raptus che non gli permetteva di staccare le mani dal collo della donna. Il suo intento iniziale era quello di farla a pezzi, inserirli in sacchetti di plastica di cui si era già dotato e di spargerli per la regione. Il primo sacchetto sarebbe stato destinato a Lignano. L'uomo, sospettato anche di altri omicidi con modus operandi analogo, ha sempre negato.

\section{Analisi vittimologica e modus operandi}

All'epoca dei fatti, nella città di Udine come tutto in tutto il resto d'Italia, l'attenzione era totalmente concentrata sulle Brigate Rosse e sul terrorismo. L'assassino si muoveva nella parte più nascosta della città, senza attirare troppo l'attenzione. Nella realtà dei fatti, rappresenta uno degli assassini più spietati dell'intera nazione. Allora perché, seppur siano passati oltre 30 anni ormai, rimane ancora un fatto sconosciuto a molti?

Le vittime del Mostro di Udine erano quasi tutte prostitute; donne emarginate dalla società, con pochi amici, che vivevano nel buio. Dagli stessi concittadini, quella categoria di donne era considerata di serie B, e quindi poco importante. Forse, se l'assassino avesse concentrato le sue attenzioni su qualche personaggio più di spicco all'interno della società, l'attenzione mediatica sarebbe stata diversa. O semplicemente, indagare sulle vittime, conoscere la loro storia, le loro abitudini e conoscenze presupponeva una perfetta conoscenza del mondo notturno della cittadina. La più grande difficoltà rimaneva sempre quella di capire chi potesse essere il colpevole, perché, in quel mestiere, ogni cliente rappresenta un potenziale assassino. Il Mostro di Udine, comunque, aveva dato ampia dimostrazione di essere sì un pazzo, ma di non essere del tutto ingenuo e sprovveduto.

Della lunga serie di omicidi che hanno interessato la cittadina di Udine tra il 1971 e il 1989, soltanto quattro sono stati ufficialmente attribuiti alla mano del Mostro di Udine.

- Maria Carla Bellone, una prostituta di 19 anni, uccisa il 16 febbraio 1980;

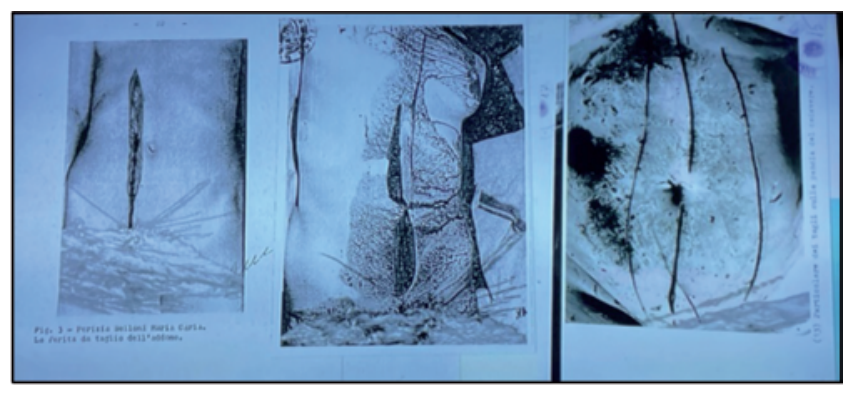

Fig. 1. ${ }^{4}$
- Luana Giamporcaro, una prostituta di 22 anni, uccisa il 24 gennaio 1983;

- Aurelia Januschewitz, una prostituta di 42 anni, uccisa il 3 marzo 1985;

- Marina Lepre, maestra di scuola elementare, uccisa il 25 febbraio 1989.

Nel 1995, il Maresciallo di Udine, sotto consenso della Procura, chiese al Medico Legale Carlo Moreschi di trovare delle caratteristiche comuni a tutte e quattro le vittime al fine di comprendere se gli omicidi fossero effettivamente collegati tra loro. Dalla consulenza emerse che:

- I tagli inflitti all'addome delle vittime non sono serviti a procurare loro la morte.

- Non c'è presenza di segni di difesa da parte delle vittime.

- Quei segni avevano un significato simbolico.

- Tutte e quattro le vittime, saltuariamente o abitualmente, si prostituivano.

La prima vittima presentava un taglio sul ventre. La seconda vittima, invece, ne presentava due. La terza vittima aveva due tagli che andavano dalla zona mammaria fino al pube, più un altro taglio obliquo (Fig. 1). L'ultima vittima, Marina Lepre, diversamente dalle precedenti, presentava soltanto un taglio. Sul fianco, però, erano evidenti dei piccoli segni, come se l'assassino avesse cominciato a farne degli altri, ma fosse stato interrotto a metà della sua opera. L'ipotesi, quindi, fu che la sua firma avesse un valore simbolico; quello di numerare le sue vittime.

Un ulteriore dato che saltò all'occhio degli inquirenti fu che sulla scena non vennero mai riscontrate tracce che facessero in qualche modo pensare che l'omicidio era stato commesso nello stesso luogo del ritrovamento. I cadaveri delle vittime, inoltre, non erano mai sporchi di sangue, cosa piuttosto inverosimile visto il modus operandi con cui venivano uccise. Questo stava a significare che l'omicidio non era avvenuto nel luogo di ritrovamento dei corpi, ma l'assassino li aveva spostati post mortem (Fig. 2).

\section{Circostanze}

Il Mostro di Udine era solito agire di notte, principalmente durante i fine settimana, prendendo di mira le zone di periferia della città, soprattutto quelle dotate di una scarsa illuminazione. I cadaveri vennero ritrovati sporchi di fango, oppure in zone piuttosto fangose. Ciò stava a significare che l'assassino agiva nelle notti piovose. A parte i due casi verificatisi a Udine, nel centro città, nelle altre occasioni il corpo della vittima era sempre stato ritrovato in zone periferiche.

\section{La firma del serial killer}

I corpi delle vittime presentavano dei tagli sul ventre, partendo dall'addome fino al pube, con particolare attenzione a evitare l'ombelico. Questi tagli erano stati inflitti con un oggetto appuntito; si parlò di un bisturi, perché le modalità di incisione erano simili a quelle praticate in ostetricia. Ci si trovava davanti a tagli molto precisi, inflitti con una certa determinazione, a mano ferma. Questo portò a supporre che l'uccisore potrebbe essere stato un medico, ma tutt'oggi, è bene sottolineare che queste rimangono tutte supposizioni. Di certo c'è che quelle lesioni erano simili a quelle che venivano insegnate nelle università di medicina fino agli anni '70, per effettuare dei tagli cesarei post mortem. Questa

4 Lena M, Agostini F (2019), Documentario Il Mostro di Udine. Ascent Film s.r.l. 
pratica riguardava le principalmente le prostitute che morivano mentre erano in attesa; gli veniva tagliato il ventre in modo tale da esportare il feto e seppellirlo lontano dalla madre. Si trattava di un gesto simbolico, per dare al bambino una sua identità nel momento del trapasso. In questo caso specifico, però, venne definita come la

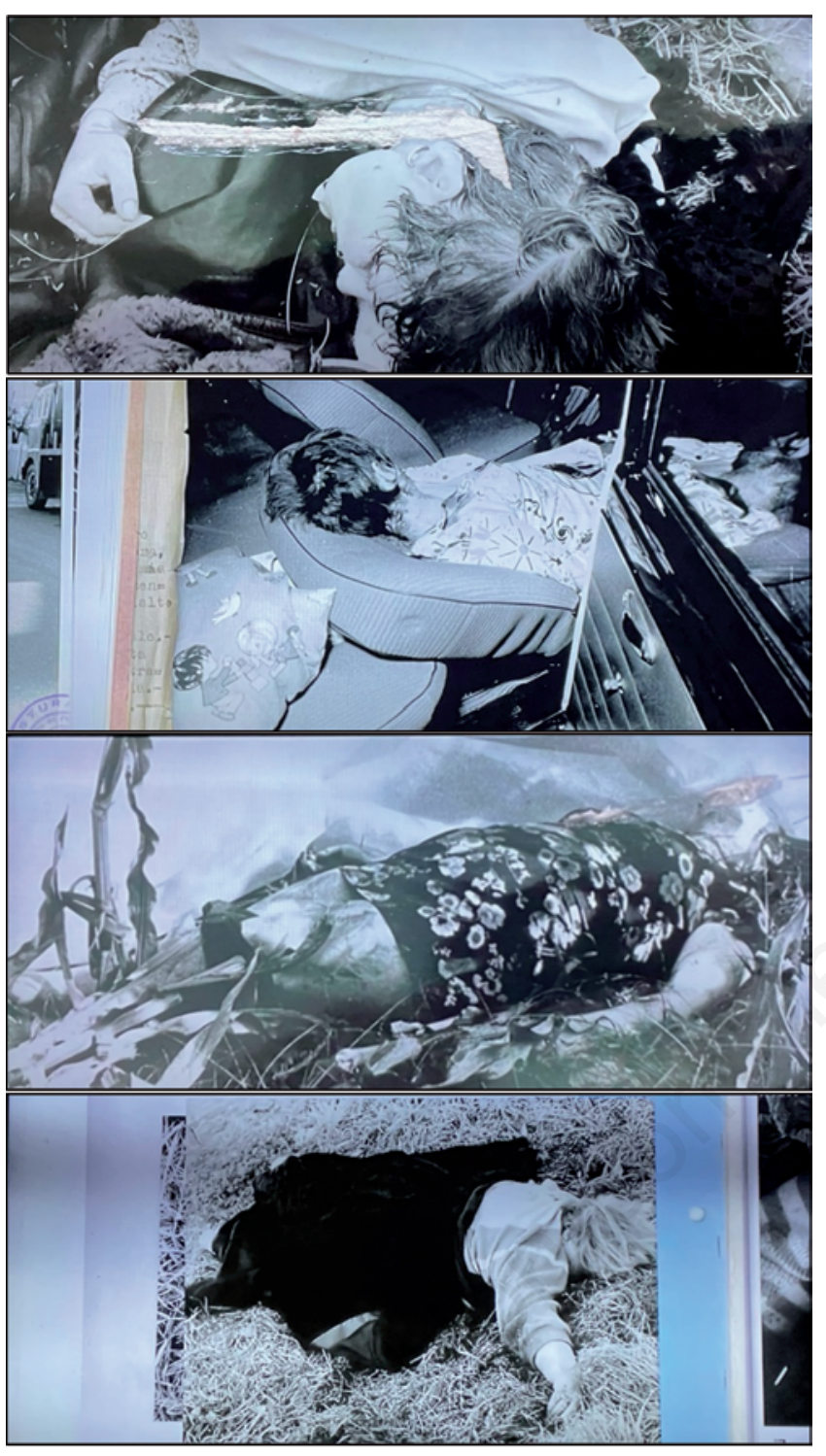

Fig. 2.5

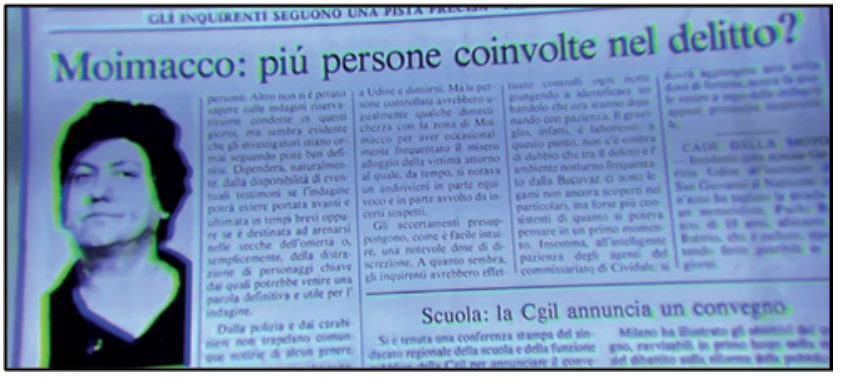

Fig. 3. ${ }^{6}$ "firma ad S", perché la forma delle incisioni ricordava la lettera S. In nessun caso ci si è trovati davanti a segni di rapporto o violenza sessuale, e nemmeno a lesioni di difesa; questo significa che colpiva le vittime di sorpresa, nel momento in cui erano più vulnerabili, senza dar loro modo di fuggire.

\section{Posizione sociale delle vittime}

La scelta delle vittime non era assolutamente casuale, ma anzi, il serial killer era solito sceglierle in modo molto preciso. La sua ira si abbatteva su donne fragili, socialmente emarginate, che soffrivano di problemi di depressione o tossicodipendenza. Nello specifico, tre vittime su quattro erano prostitute. Per questo motivo, l'ipotesi iniziale fu quella di un giustiziere, che uccideva le prostitute allo scopo di "purificare" la città. Questa ipotesi venne eliminata con l'ultimo omicidio, quello di Marina Lepre, l'unica vittima a non essere una prostituta. Erano tutte persone che non potevano lasciare tracce. Conseguentemente al lavoro che svolgevano, si muovevano per la città principalmente durante la notte, senza prendere degli appuntamenti fissi. Questo rendeva molto difficile intercettarle, e conoscerne gli spostamenti nelle ore precedenti alla loro morte.

Per quanto riguarda i delitti di:

- Irene Belletti, uccisa il 21 settembre 1971

- Maria Luisa Bernando, uccisa il 20 settembre 1976

- Jacqueline Brechbuhler, uccisa il 29 settembre 1979

essi presentano caratteristiche simili ai quattro sopraelencati dal punto di vista della vittimologia, ma prevedono un modus operandi diverso. La morte non è avvenuta per strangolamento né per sgozzamento, inoltre sulle vittime non è presente la "firma del mostro", ovvero l'incisione nella zona addominale.

Tra di loro, però, questi tre omicidi presentano delle analogie dal punto di vista vittimologico e del modus operandi, cosa che fa ipotizzare che siano stati effettivamente opera di uno stesso autore. Inoltre, sono stati commessi nello stesso periodo, ovvero negli ultimi giorni di settembre. Succede a volte, infatti, che l'autore commetta diversi omicidi nello stesso periodo dell'anno, perché spinto da un ricordo traumatico.

Nel solo anno 1984, sono state trovate morte due donne:

- Maria Bucovaz, uccisa il 20 maggio 1984

- Stojanka Jokimovic, uccisa il 29 dicembre 1984

Due vittime in età avanzata, 42 e 44 anni, corpi molto robusti, strangolate con una calza di nylon. Il fatto che fossero entrambe donne con una corporatura piuttosto importante, e quindi piuttosto complicate da affrontare, fa presumere che conoscessero e si fidassero del loro assassino. Inoltre, i loro cadaveri erano stati spostati in post mortem; questo fece presumere che l'assassino non agisse da solo ma si facesse aiutare da qualcun altro (Fig. 3).

Nello stesso anno era stato rinvenuto anche il corpo di Matilde Zanette Bazzo, morta per soffocamento. Non è stata presa in considerazione nell'elaborazione di questa classificazione, in quanto, per questo omicidio è stato arrestato e poi condannato Gianluigi Sebastianis, un falegname di 25 anni che in un primo momento confessò, per ritrattare subito dopo la sua colpevolezza e dichiararsi innocente.

Anche queste due vittime vennero attribuite ad una stessa mano.

Ci si trovava di fronte a più mostri, o ad un'evoluzione dello stesso?

5 Ivi.

6 Articolo tratto da "Il Messaggero Veneto"- https://messaggeroveneto.gelocal.it/udine 


\section{Il sospettato}

Il sospetto che dietro ai 14 omicidi si nasconda lo stesso uomo, nasce nel febbraio del 1989, dopo il ritrovamento del cadavere di Marina Lepre.

I delitti avevano delle caratteristiche comuni, che fecero pensare agli inquirenti che non si trattasse di una semplice coincidenza. Un uomo, che nutre del forte odio nei confronti del genere femminile, di cui ne conosce a memoria l'anatomia. In particolare, fu proprio quel taglio inflitto alle vittime, fatto con una tale precisione, a far nascere l'idea che l'assassino fosse un chirurgo. Quei tagli sono compatibili con le tecniche che all'epoca venivano impiegate nei parti cesarei. Un uomo fragile, evidentemente psicopatico, la cui frustrazione anche sessuale, è stata incanalata ed espressa in follia omicida.

Si parla di un "mistero italiano", una serie di vicende a cui non è mai stata data una spiegazione. Sebbene quello del Mostro di Udine sia un crimine tutt'ora irrisolto, rimasto sospeso nell'aria, c'è stato un sospettato, mai ufficializzato per mancanza di prove.

È il 25 febbraio 1989, sul luogo del ritrovamento del cadavere dell'ultima vittima, i carabinieri si imbatterono in un uomo di avanzata età.

Lo portarono in caserma per dei controlli, durante i quali l'uomo ha più volte sottolineato di non frequentare donne, e di preferire la campagna alla città, poiché troppo rumorosa e trafficata. Edi Sanson mostra all'uomo le foto del cadavere di Marina Lepre per un riconoscimento, ma l'uomo si ammutolisce e non collaborerà più.

Dalle indagini, emerse che il sospettato proveniva da una famiglia molto benestante e conosciuta in città. Era il secondo di tre fratelli. Si laureò in medicina con specializzazione in ostetricia ma non poté mai svolgere la sua professione perché gli venne diagnosticato un disturbo schizofrenico con aspetti di carattere paranoide e una misoginia aggressiva nata dal rapporto dell'individuo con la madre.

Nella camera da letto dell'uomo vennero ritrovati degli appunti di medicina, dei vestiti da donna e un set di strumenti chirurgici da cui mancava il bisturi. Nonostante questo, dal momento in cui la famiglia del medico viene messa sotto stretto controllo da parte delle forze di polizia, i delitti cessarono.

Dopo un periodo di tranquillità, il Giudice definì tutti gli indizi raccolti fino a quel momento come delle semplici prove non sufficienti ad incastrare l'uomo, e nel 1997 decise di archiviare nuovamente il caso perché ad opera di ignoti. Nel 2006 l'unico sospettato muore, e con lui, si estinse anche il reato. Nel 2019, in occasione delle riprese del Documentario sul Mostro di Udine, venne richiesta la riapertura delle indagini, sulla base di due elementi mai stati esaminati: un profilattico usato e uno spinello.

\section{Serial killer: definizioni e classificazioni}

Il Mostro di Udine ha terrorizzato la cittadina dal 1974 al 1985. Ad oltre 30 anni distanza, rimane un assassino senza volto. Non si conosce il motivo che lo ha spinto ad agire in quel modo, né il perché abbia preso di mira proprio quelle donne. L'unica notizia certa che si ha sul suo conto è che sia entrato ufficialmente a far parte dei serial killer italiani.

Ma che cosa significa il termine "assassino seriale", e in che cosa si differenzia da un omicida comune? Fino agli anni '50, questo termine non esisteva. Per riferirsi ai criminali che uccidevano più di una vittima, veniva utilizzato il termine "assassino multi- plo", senza fare alcuna distinzione dal punto di vista del modus operandi. Col passare del tempo si è sviluppato un forte interesse nei confronti di questa figura, che non veniva più vista solo come una figura negativa, ma nasceva verso di essa un sentimento di ammirazione nei confronti delle sue gesta. Alla figura del serial killer vennero dedicati romanzi, serie televisive e film.

Risale al 1888 il primo tentativo di designazione di un profilo criminologico di un individuo, in particolare con Thomas Bond, medico legale che venne chiamato in aiuto dalla Polizia inglese nella ricerca del serial killer più famoso della storia, Jack Lo Squartatore.

Fu Robert Ressler, agente speciale dell'FBI, ad utilizzare per la prima volta in assoluto nel 1957 il termine "serial killer", per riferirsi a coloro che avevano commesso almeno tre omicidi, lasciando passare un determinato lasso di tempo tra essi. Per giungere a queste conclusioni, prese in esame 36 detenuti americani, tutti assassini.

Questo lasso temporale, che può variare da ore a mesi o addirittura anni, viene definito come "cooling of time" e serve a dare un'informazione importante sulla vita dell'assassino. Essi pensano e agiscono rispettando un ciclo:

- Eccitazione progressiva

- Fantasie e pianificazione dell'evento

- Realizzazione dell'evento

- Scarica emozionale successiva al delitto

Molto spesso questi soggetti hanno una vita normalissima, con una famiglia, dei figli e un lavoro.

La classificazione ufficiale fatta dall'FBI nel 1979 vede una distinzione all'interno della grande categoria dell'omicidio multiplo.

- Mass murderer: omicidio di massa. Uccisione di 4 o più vittime per mano di uno o più autori, in un unico evento. Il mass murder avviene in un unico determinato luogo, e rappresenta una sorta di rivendicazione nei confronti della società, per questo, una volta portata a termine, la missione si conclude con il suicidio o con l'uccisione dell'assassino da parte delle forze dell'ordine. Il movente è la frustrazione nei confronti degli ingiusti persecutori, poco importa se sia reale o meno; è frutto di un delirio paranoico di mente malata.

- Spree killer: omicida compulsivo. Uccisione di più vittime in diversi luoghi. Non c'è razionalità, l'autore è mosso dall'impeto e dalla rabbia; per questo, non c'è la fase di raffreddamento emozionale, l'omicidio avviene in un unico evento. Come nel caso del mass murder, l'autore non si nasconde e viene ucciso, o muore suicida. Il movente è la ricerca di distruzione.

- Serial killer: assassino seriale. Tre o più eventi omicidiari, commessi in tre luoghi differenti, separati da un intervallo di "raffreddamento emozionale". Sceglie le sue vittime o colpisce a caso. Esiste in lui la convinzione di essere invincibile.

Negli ultimi anni, l'FBI ha ritenuto poi sufficienti due eventi omicidiari, non più tre, per poter parlare di assassino seriale. Non rientravano a farne parte il Double Killer (due vittime, nel medesimo momento e luogo), e il Triple Killer (tre vittime, nel medesimo momento e luogo).

La classificazione fatta dall'FBI è importante perché, per la prima volta, sono state introdotte delle nuove figure all'interno del grande gruppo dell'omicidio multiplo. Questo sottolineava la necessità di intraprendere nuovi studi in merito. Per quanto innovativa, questa teoria oggigiorno non è più utilizzata perché considerata ormai inattendibile.

Nel 1995, Vincenzo Maria Mastronardi e George B. Palermo, basandosi sulla precedente di Holmes e De Burger, hanno fatto una nuova classificazione di serial killer, analizzandone 5 diverse figure: 
- Serial Killer Visionario. Questo assassino seriale commette gli omicidi in conseguenza a degli ordini che è convinto di avere ricevuto in seguito di allucinazioni visive o uditive (il soggetto "sente" delle voci che gli dicono di fare qualcosa oppure ha delle "visioni" che assolvono lo stesso compito). Si tratta di vere e proprie "allucinazioni di comando" in cui la "voce" percepita di solito è quella di Dio o di Satana che fornisce indicazioni pratiche per commettere l'omicidio. I soggetti che hanno allucinazioni visive sono convinti di essere posseduti da una specie di demone soprannaturale e la maggior parte di essi mostra un quadro patologico piuttosto grave nel quale le diagnosi più comuni sono schizofrenia di tipo paranoide oppure disturbo allucinatorio paranoide: nel primo caso, di solito, gli omicidi presentano elementi bizzarri e di scarsa organizzazione, mentre nel secondo il livello di pianificazione è sicuramente più elevato.

- Serial Killer Missionario. L'assassino seriale di questo tipo è convinto di avere il compito di portare a termine una specie di "missione divina" che lo vede nel ruolo di colui che ripulirà il mondo da persone considerate indesiderabili (prostitute, vagabondi, spacciatori di droga ecc. Generalmente, questo soggetto non soffre di una psicosi, ma spesso è condizionato da convinzioni personali sostenute da alcune false percezioni di tipo paranoide; non prova neanche rimorso per le sue azioni, in quanto è convinto che sta eseguendo un compito che gli è stato assegnato "direttamente" da Dio e che serve "per migliorare la società".

- Serial Killer Edonista. È un serial killer che prova un particolare piacere nell'atto di uccidere. L'azione omicidiaria possiede un valore intrinseco autonomo e fornisce all'assassino una sensazione di soddisfazione paragonabile a una specie di "orgasmo emotivo", come quello sperimentato dal giocatore d'azzardo che scommette in maniera pesante e aspetta i risultati, o come la sensazione di eccitazione provata da tutte quelle persone che intraprendono attività particolarmente rischiose (praticare la "roulette russa" con una pistola, dedicarsi a uno "sport estremo", ecc.) perché hanno bisogno di sperimentare forti emozioni per "sentirsi vivi".

- Serial Killer del Controllo del Potere. Questo omicida seriale persegue in prevalenza lo scopo di esercitare il controllo assoluto su di un'altra persona, per deciderne la vita e la morte e sentirsi, in tutto e per tutto, simile a Dio, in una ricerca dell'onnipotenza totale. L'eventuale stupro, sodomizzazione e/o mutilazione del corpo della vittima, in questo caso, non ha una reale motivazione di tipo erotico e il sesso viene utilizzato soprattutto come strumento per esercitare il potere e raggiungere il completo controllo psicofisico della vittima.

- Serial Killer Lussurioso ("Lust Killer"). In questo caso, 1'obiettivo primario dell'assassino non sembra tanto quello di esercitare il potere, quanto piuttosto quello di ottenere un soddisfacimento di tipo prettamente sessuale. Di solito, il soggetto che rientra in questa categoria è caratterizzato dalla presenza di iperstimolazione organicosessuale dovuta a uno scompenso ormonale che, in sede trattamentale, può essere drasticamente ridotta con una terapia farmacologica ormonale riequilibrante, una specie di "castrazione chimica". Nelle genesi dei delitti di questo assassino, le fantasie giocano un ruolo di primo piano e sono orientale in chiave di perversione sessuale (sadismo, feticismo, ecc.) e di bisogno di mutilare, squartare e deprezzare il corpo della vittima. ${ }^{7}$

\footnotetext{
7 Paragrafo da Mastronardi VM e De Luca R (2013), I Serial Killer,
} Newton Compton Editori, pg.68-70.

\section{Estratti delle interviste}

\section{Edi Sanson}

\section{Intervista a Edi Sanson, ex carabiniere, in servizio all'epoca dei fatti}

Edi Sanson, nel 1989 lei prestava servizio come carabiniere nella città di Udine. Il 26 febbraio 1989 ha ricevuto la chiamata del ritrovamento di un cadavere, quello che poi si sarebbe scoperto essere di Marina Lepre. Può ricostruire quanto accaduto quel giorno?

Io intervengo su Marina Lepre, ma come su altri delitti, in una fase di inizio delle attività da carabiniere. L'attività investigativa all'epoca veniva svolta palmo a palmo, ci si basava sulla conoscenza del luogo, delle persone, e sulle loro parole; non esistevano ancora le telecamere, i tracciamenti telefonici. Quasi nessuna delle vittime del c.d. Mostro di Udine può considerarsi una persona censita, sì conosciuta dalle Forze di Polizia, ma non censita alla banca dati del DNA o delle impronte digitali. Ė stato possibile riconoscere il cadavere grazie ai punti di sutura presenti sul mento. Senza quelli, avremmo dovuto aspettare la denuncia di scomparsa. Fosse accaduto oggi, avremmo potuto rilevare le impronte digitali direttamente sul campo, e interrogare la banca dati del luogo del ritrovamento. All'epoca, non esisteva nulla di tutto ciò. I fascicoli di Marina Lepre e delle altre vittime contenevano poche pagine di investigazione.

Qual era l'iter da seguire una volta arrivati sul luogo del ritrovamento del corpo?

Esamino il corpo. Ci viene poi data l'autorizzazione a ruotare il corpo, per permetterci di visionarlo meglio. È lì che ho visto lo squarcio che mi ha profondamente colpito e ha fatto nascere un senso di responsabilità nei confronti della vittima. C'è un'immagine di Marina Lepre, che è ben impressa nella mia memoria, con cui io continuo a identificarla. Il maglioncino di colore giallo, la gonna a pois, i capelli bagnati e tutta la sofferenza che esprimeva la situazione.

In che preciso momento è maturata dentro di lei l'idea che ci potesse essere un solo assassino dietro a più omicidi?

Per spiegarlo, è necessario fare prima un passo indietro. Io conoscevo i delitti attribuibili a una stessa mano; in qualche occasione era stato nominato anche il Mostro di Udine, ma questi delitti erano tutti chiusi in un raccoglitore. Oggi un'indagine è composta da $15 / 20$ faldoni a episodio, all'epoca un faldone conteneva più fascicoli di indagine con la scritta "omicidi". La curiosità per questi delitti mi ha spinto a sfogliare questi fascicoli, inizialmente durante le pause o nei turni notturni. Nel momento in cui c'è stata la rotazione del corpo di Marina Lepre, lo squarcio alla gola e la località di abbandono del corpo mi hanno immediatamente fatto pensare: "È tornato. È tornato il Mostro".

La località in cui è stato rinvenuto il corpo è praticamente identica per almeno 4 dei delitti a lui attribuiti; il punto era costeggiato da gelsi, utilizzati per dividere le proprietà. Al termine del filare dei gelsi, o nel mezzo, era stato abbandonato il corpo. È vero anche che è un albero piuttosto frequente nella campagna friulana, ma, facendo riferimento alle fotografie riportate dai giornali dei luoghi in cui sono stati ritrovati i corpi delle altre vittime, richiamava immediatamente alla memoria il modus operandi dell'assassino.

All'epoca c'era una carenza di elementi all'interno dei fascicoli, ad esempio per quanto riguarda il lavoro del medico legale, che veniva incaricato dalla Procura della Repubblica; le autopsie non facevano parte del fascicolo d'indagine. Oggi invece lavora in parallelo all'attività investigativa.

La sera del 26 febbraio 1989, lei e il suo collega, durante il turno siete tornati sul luogo del ritrovamento del cadavere. $\grave{E}$ 
proprio lì che avete visto l'uomo che poi sarebbe diventato l'unico sospettato di tutta la vicenda.

Dopo l'identificazione della vittima, c'è stata la necessità di percorrere la città in lungo e in largo per riuscire ad ottenere delle informazioni sulla sua presenza. Era stata vista per l'ultima volta in via Cividale, in questo bar dove aveva avuto una discussione con i due militari. Ultimata questa fase, c'è stato un briefing all'interno della caserma, dove un mio collega mi ha ripetutamente chiesto di ritornare sul posto del ritrovamento. Per dargli la soddisfazione siamo tornati, imbattendoci in queste luci di un'automobile. Abbiamo visto questa macchina e abbiamo pensato che fossero dei nostri colleghi, che per fatalità quel giorno mancavano dall'ufficio. Anche perché non si trattava di un luogo di passaggio; era un punto isolato in cui ci si doveva andare appositamente. Quindi la nostra deduzione è stata: "Sono loro, facciamogli uno scherzo e spegniamo i fari". Più ci avvicinavano al punto, più ci pareva inverosimile la presenza dei nostri colleghi lì. Fino a che, una volta più vicini all'auto, abbiamo visto la sagoma e i due fari circolari caratteristici del maggiolone, allora abbiamo subito compreso che non poteva trattarsi di un'auto di servizio e abbiamo acceso i fari. L'abbiamo fatto più che altro affinché non ci potessero dire niente; pensavamo potesse essere la questura, o qualche addetto ai lavori. Accostati all'auto abbiamo capito che le nostre supposizioni erano del tutto errate; quindi, abbiamo proceduto ad un controllo piuttosto blando, fatto più per giustificare la nostra presenza sul posto. C'è stata la richiesta della patente e del libretto. Non siamo scesi dall'auto, ci siamo semplicemente affiancati, in un'operazione piuttosto rischiosa. Nell'89 non siamo lontani dal terrorismo, quindi c'era un protocollo piuttosto rigido da rispettare che gli ufficiali ci ripetevano nella continua istruzione settimanale. All'epoca i furti erano all'ordine del giorno. Il nostro approccio è stato del tutto fuori luogo e sconsiderato, anche per due giovani carabinieri. Siamo arrivati sul posto pensando potessero essere dei colleghi a cui fare uno scherzo, poi abbiamo operato un controllo per giustificare noi la nostra presenza. Non abbiamo nemmeno chiesto il nominativo al terminale, soltanto la richiesta di un documento. L'uomo mi ha dato la sua carta d'identità e non la patente richiesta. Quando l'ho avuta in mano sono rimasto basito nel vedere scritto "professione: medico chirurgo", associandolo a quello che era lo squarcio sulla vittima e alle mutilazioni già attribuite ipoteticamente alla mano di un chirurgo. Nella mia carriera ne ho viste di ogni, ma in quel contesto, l'aver agito in maniera così sprovveduta, la sua vicinanza, la sua figura e il luogo, mi hanno subito fatto pensare di aver commesso un grave errore. Gli ho subito restituito il documento, e senza neanche prendere nota, siamo andati avanti, lasciandolo lì. Non saprei dire se fosse un pericolo, o una persona che non c'entrava assolutamente niente. Poi c'è stato il pedinamento e l'episodio in cui l'individuo è apparso in tutta la sua stranezza. È stato accompagnato in centrale, dove ha continuato a dare dimostrazione di essere un soggetto particolare, dopodiché insieme al Colonello lo abbiamo riaccompagnato a casa. Qui ci siamo imbattuti nella figura dell'avvocato, suo fratello, che è stato poi chiamato in caserma il giorno seguente. La situazione aveva comunque destato curiosità e attenzione. Dopo l'audizione del fratello, che si è premurato di coprire il chirurgo fermato il giorno prima, è tornato nella sua oscurità e per anni non è più stato interpellato. Anche perché, da quel momento delitti non ce ne sono più stati. La figura del chirurgo ritorna sulla scena qualche tempo dopo, parlando con un collega, "Parlare", negli anni è poi diventata la chiave vincente del mio modo di fare; se io ne parlo con più persone, loro trasmetteranno a me le loro conoscenze. Mentre noi eravamo stati indottrinati alla riservatezza dell'ufficio, ovvero c'era il divieto di divulgare informazioni in merito alle indagini fuori dal luogo di lavoro, tanto che la divulgazione di segreto d'ufficio è un reato. Regola che nel proseguo della mia attività poi ho sempre disatteso poi, perché ho realizzato che parlandone, con i dovuti modi, si aveva un riscontro molto vantaggioso al fine delle indagini. Non serviva bussare porta a porta per cercare qualche informazione, era sufficiente bussare alle porte giuste. Una rete informativa fatta non dal confidente, ma fatta da comuni persone che avevano un ruolo nella società.

\section{Si ricorda com'era l'uomo?}

Quella sera ho visto soltanto un mezzo busto; lo rividi meglio una volta in caserma. Era un uomo alto, molto magro, scavato. Era silenzioso, piuttosto difficile da ascoltare, Negli anni ho poi avuto modo di fare esperienze che mi hanno permesso di affinare la mia tecnica di interrogatorio e ottenere così la confessione per molti delitti, Beh, quello lì è stato un vero e proprio fallimento. Probabilmente dato dall'inesperienza, però lui era un soggetto molto particolare e molto difficile da interrogare, infatti non fu mai più interrogato. Le uniche quattro parole che aveva riferito riguardanti la sua presenza sul luogo del delitto sono state del tutto contradditorie, non ha mai fornito elementi importanti. Diciamo che anche se non del tutto corretto, io l'ho sempre visto come un attore che impersonava il ruolo di Dracula, molto scavato. Sotto la luce in ufficio era secondo me una persona inerme, probabilmente anche in difficoltà ad interfacciarsi. Mi ricordo che gli feci vedere la foto di Marina Lepre, e lui reagì male. Mi disse solo: "Io non do mai passaggio a donne", dopodiché si chiuse. L'avevo illuminato con una lampadina per poter visionare meglio il documento, e l'ombra creata dalla luce lo faceva apparire come davvero inquietante, spaventoso. Vedendolo però poi negli anni diciamo che sembrava più un anziano qualunque, molto magro, chiuso, restio nel dare confidenza. Non sembrava assolutamente un soggetto pericoloso.

Marina Lepre, l'ultima vittima ufficialmente attribuita alla mano del c.d. Mostro di Udine, non era una prostituta ma una maestra di scuola elementare. La considera un errore?

In realtà poteva essere tranquillamente confusa per una prostituta. Tra le altre cose, anche la sera del delitto, un sabato, io ero in servizio, e mi ricordo che pioveva a dirotto. Marina Lepre la segnalano in due punti della città: prima in quel bar, dove per una questione piuttosto logica, lei poteva fare autostop per ritornare a casa, perché effettivamente era nella giusta direttrice di marcia. L'avvistamento però è stato fatto molto in anticipo rispetto a quella che è l'ora del delitto. L'altro punto, invece, è la zona dell'ospedale di Udine, ad un orario molto avanzato, verso le 23.30, più compatibile con l'orario della morte. È stata avvistata mentre attraversava Piazza Chiavris in direzione Piazza Medaglie d'Oro. All'epoca le prostitute erano più localizzate nella zona della stazione, non ne ricordo nella parte nord della città. Non siamo però molto lontani da quella che era l'abitazione del chirurgo, si parlava di qualche centinaio di metri. Il pensiero che agisse nelle sere di pioggia trova conferma in tutte le vittime tranne una, che invece è stata ritrovata completamente asciutta, su un terreno asciutto. Marina Lepre era totalmente bagnata, mi ricordo i suoi capelli schiacciati dalla pioggia. Esce dal bar alle 19.00 quando il cielo è ancora sereno, mentre alle 23.30 c'è una pioggia battente molto insistente. È chiaro che se fosse morta alle 19.00 e solo successivamente esposta all'acqua non cambierebbe nulla, ma effettivamente la presenza della pioggia era una delle analogie che si stavano riscontrando. Credo personalmente che sia più indifesa una persona che, o per necessità, come nel caso di Marina Lepre che doveva fare rientro a casa, o per abitudine, le prostitute salgono in macchina per esercitare la professione, in entrambi i casi la capacità di valutare un pericolo, sia inferiore in caso di pioggia. Non si valuta chi si ha di fronte, la priorità è salire in macchina per ripararsi. È un po' uno stratagemma che viene utilizzato dall'assassino, sfruttare le condizioni climatiche per ottenere una minore resistenza da parte della vittima prescelta. In tutta la storia non abbiamo però dei precedenti, di qualche donna che ha raccontato di quest'uomo, di aver opposto resistenza e della sua fuga. $\mathrm{O}$ ha fatto un tiro, un centro, o le informazioni 
esistono ma non sono convogliate nei fascicoli di indagine. L'attività investigativa era slegata anche tra i singoli reparti, le informazioni all'epoca non venivano messe a disposizione degli investigatori in una banca dati.

Ad oggi, alla luce di tutto ciò che accaduto, dopo oltre 40 anni dal primo delitto, basandosi sulla sua esperienza, che idea si è fatto in merito?

Specifico che io nasco investigatore. La responsabilità di arrestare un innocente è un qualcosa di estremamente pesante, pertanto, non partire da zero e non dare pari opportunità a tutti i soggetti che entrano a far parte dell'indagine, rischia di creare dei grossi danni. Come precedentemente detto, piccoli indizi, piccoli fatti, fanno certamente propendere per una partecipazione alla vicenda da parte del chirurgo. Sono luoghi comuni, pensiamo a "l'assassino torna sempre sul luogo del delitto". È possibile. Ha dimenticato qualcosa, sente un impulso. È capitato davvero di tutto. Però, possono anche essere tutte delle coincidenze. Dal punto di vista caratteriale, questo soggetto aveva degli elementi per poter essere l'assassino, però non siamo in grado di collocarlo nel tempo, proprio a causa della carenza di informazioni. Per quanto riguarda le autovetture utilizzate dal Mostro, per esempio, le informazioni acquisite sono le più disparate: una Simca, una Mercedes, etc. Non ci sono nemmeno degli elementi comuni a tutte le informazioni. Per Marina Lepre effettivamente il collegamento c'è, ma, se davvero del Mostro si tratta, come lo collochiamo nelle altre situazioni? Abbiamo trovato un preservativo all'interno dell'autovettura di Maria Luisa Bernardo, che è ancora in fase di analisi, ma oggi questo compito non spetta più a me. Lo abbiamo ritrovato all'interno dei faldoni, perché all'epoca dell'accaduto non aveva un'utilità scientifica forense. Da quel profilattico avremmo potuto semplicemente risalire al gruppo sanguigno, o forse a un DNA che però non sarebbe poi stato utilizzato per mancanza di strumenti. Oggi, a 44 anni di distanza, quel profilattico contiene due DNA, uno all'interno e uno all'esterno, uno di donna e uno di uomo. Lo stesso discorso vale per lo spinello ritrovato sulla scena del crimine di Maria Carla Bellone, che contiene una doppia traccia di un uomo e una donna. Si tratta di un cliente che aveva ricevuto nello stesso posto, qualche tempo prima? Sarebbe interessante scoprirlo, per identificarlo e scoprire chi fosse. Il profilattico si trovava all'interno dell'autovettura di Maria Luisa Bernardo, se non dell'assassino, magari poteva essere del cliente precedente. Se ancora in vita, potrebbe darci delle informazioni importanti. Oggi noi viviamo in un momento dove, anche il fatto che tu abbia spinto la porta di ingresso ci consente di trovare una traccia. Possiamo ricostruire i passi che hai fatto, per dedurre su quale sedia tu ti sia seduta. All'epoca non c'era questa esperienza, non c'era questa possibilità. Se noi avessimo prelevato e conservato tutti i reperti, oggi avremmo potuto riesaminarli. Molti di essi sono andati persi, perché sono stati ritrovati da Carabinieri che non facevano parte dell'indagine, perché a Pradamano all'epoca intervenne la Polizia, Non sapendo cosa farne, li hanno spillati all'interno del fascicolo processuale; stessa sorte sarebbe dovuta capitare al profilattico, che è stato dato al medico per l'autopsia, ma risultando inutile a quel fine, è stato reinserito nel fascicolo processuale. Lo possiamo considerare quasi un errore di procedura, perché sarebbe dovuto andare all'Ufficio Reperti, e oggi noi non l'avremmo più. Pur seguendo l'iter corretto, avremmo disperso le uniche prove disponibili. Sbagliando, quindi, siamo riusciti a preservarlo. Così non è stato invece per l'autovettura della vittima. Durante le riprese del Documentario ${ }^{8}$, spinti dalla situazione nuova, abbiamo raccolto più elementi rispetto a quelli che avevamo raccolto nel 1994/1995. Abbiamo avuto modo di vedere tutti i fascicoli della Polizia che da Carabinieri e investigatori non avevamo avuto modo di visionare, perché non c'era quella collaborazione che c'è invece oggi. È cambiato tutto. Oggi l'assassino non l'avrebbe fatta franca.

\section{Carlo Moreschi}

Intervista a Carlo Moreschi, medico-legale che all'epoca si occupò della perizia medica su 4 delle vittime

Qual è stato il suo primo approccio con la vicenda del c.d. Mostro di Udine?

Io sono arrivato a Udine nel 1992, pertanto non feci nessuna autopsia sulle vittime. Venni contattato dai Carabinieri per revisionare i verbali autoptici, e le foto di, se non ricordo male, 4 casi. Il mio ruolo, quindi, è stato quello di fare una revisione, in quanto inizialmente si era escluso che dietro a questi omicidi ci fosse un'unica mano. I Carabinieri nel corso delle indagini avevano iniziato a maturare dei sospetti; pertanto, hanno contattato me in qualità di medico-legale, ovvero colui che analizza i corpi. È stato questo il mio primo approccio con la vicenda.

Lei è stato chiamato a trovare delle analogie a questi quattro delitti. Quali erano effettivamente?

La principale caratteristica, comune alle vittime, era che presentavano delle ferite post mortali, simili tra loro, Simili, non identiche. Erano tagli sull'addome, più o meno longitudinali. Uno molto lungo che passava a sinistra dell'ombelico. È stato questo che ha fatto sospettare fosse un medico, perché noi, nello svolgimento di un'autopsia, passiamo sempre a sinistra dell'ombelico. La cosa che fa propendere al fatto che siano tutte frutto di una stessa mano, è che le ferite non hanno una motivazione nell'atto omicidiario. Se io voglio uccidere una persona con un coltello, l'aggredisco in modo tale da provocarle delle lesioni utili alla sua morte. Saranno lesioni mirate ai suoi punti vitali, ma divise in diverse parti del corpo; perché si è difesa, perché l'ho colpita alle spalle, etc. Le ferite che ho riscontrato sui cadaveri non avevano un senso logico. Non erano finalizzate all'uccisione, ma erano un qualcosa che veniva fatto dopo. Per quale motivo? Si può pensare a depistaggio, ad un gesto rituale o dimostrativo. Io voglio dimostrare qualcosa, allora faccio questi sfregi sul corpo ormai esanime. Non sembrava però essere un messaggio rivolto a qualcun altro, piuttosto sembrava un rituale. Nella sua testa, lui voleva creare questa lesione a questa donna $\mathrm{X}$, che non conosceva e con cui non aveva mai avuto nessun rapporto, Se si fosse trattato di una sola vittima con questi sfregi, allora si sarebbe trattato di un solo episodio messo in atto da un solo individuo, In questa occasione, però, ci siamo trovati davanti a una serie di tagli simili tra loro, che hanno fatto pensare che con un'alta probabilità potessero effettivamente essere opera di una stessa mano. Dobbiamo anche tenere in considerazione che la figura dell'assassino seriale ha un'evoluzione nel tempo.

Ad' oggi, alla luce di tutto ciò che accaduto, dopo oltre 40 anni dal primo delitto, basandosi sulla sua esperienza, che idea si è fatto in merito?

Sulle prostitute precedenti non posso farmi un'idea perché non sono stato io a visionarle. Per quanto riguarda Maria Carla Bellone, Luana Giamporcaro, Aurelia Januschewitz e Marina Lepre, come tipologia di persone erano piuttosto simili. Tutte tranne Marina Lepre erano prostitute, ma non delle professioniste. Si tratta di persone al margine della società, con problemi di alcool o droga. Posso affermare con certezza che, secondo il mio parere, queste quattro vittime sono state uccise da una stessa mano.

8 Lena M, Agostini F (2019), Documentario Il Mostro di Udine. Ascent Film s.r.1. 


\section{Federica Tosel}

Intervista a Federica Tosel, all'epoca avvocato di Fedra Peruch, figlia di Marina Lepre. Attualmente, è l'avvocato dei parenti di Maria Carla Bellone e Maria Luisa Bernardo

Qual è stato il suo primo approccio con la vicenda del Mostro di Udine?

Specifico fin da subito che io non sono per niente convinta che ci sia un mostro, ma continuiamo a chiamarlo così. Il mio primo approccio con la vicenda del Mostro di Udine, avviene durante la mia infanzia, perché il primo Pubblico Ministero che ha indagato su questa vicenda è mio padre 9 . Mi ricordo che il primo omicidio, quello di Irene Belletti, nel 1971, avvenne il giorno dell'anniversario di nozze dei miei genitori; loro stavano festeggiando, e lui è dovuto andare. L'approccio professionale, invece, è stato diverso. Negli anni della mia formazione ho vissuto a Bologna, pertanto l'anno in cui tutta la vicenda si è conclusa, criminologicamente parlando, nel 1989, io mi trovavo a Bologna. Non mi interessavo molto dei crimini che avvenivano a Udine, ma ricordo che in quel caso, mio padre ne parlò molto in casa. All'epoca, comunque, io ero una studentessa di giurisprudenza e nulla di più. Succede però che un giorno una mia carissima amica, Elena Commessatti, decide di occuparsi di questa storia e inizia a fare delle indagini, più che altro a livello giornalistico, perché non avevamo avuto l'autorizzazione a visionare i fascicoli. Mi presenta Fedra Peruch, la figlia di Marina Lepre. A questo punto io entro a far parte della vicenda del Mostro di Udine dal punto di vista professionale, anche se in realtà la mia famiglia c'era già dentro sotto ogni punto di vista. Rappresentando Fedra, abbiamo chiesto la prima riapertura delle indagini. Sua zia le diede un anello, una collanina e uno scialle appartenuti alla madre. Fedra con questo scialle andò a Chi l'ha visto, e la Procura si interessò nuovamente al caso, sequestrò lo scialle, lo inviò ai RIS ma gli accertamenti purtroppo non portarono a nulla. Di conseguenza venne poi archiviato il caso.

Nello specifico, qual è stato il suo ruolo in qualità di avvocato?

Come ho accennato, inizialmente ho rappresentato Fedra Peruch, la figlia di Marina Lepre, ottenendo la riapertura del caso relativo a sua madre. Il Pubblico Ministero dell'epoca aveva chiesto a un medico legale, il Professor Carlo Moreschi, di redigere una prima consulenza sulle vittime Maria Carla Bellone, Luana Giamporcaro, Aurelia Januschewitz e Marina Lepre, in cui lui ipotizza un'unica mano dietro ai quattro corpi esaminati, sulla base delle ferite longitudinali inflitti alla zona addominale e toracica delle vittime. Nel fascicolo di Marina Lepre si vedono tutte le indagini svolte in merito alla vita della donna; che cosa aveva fatto i giorni precedenti, le crisi in cui aveva dichiarato che qualcuno l'avrebbe ammazzata, chi l'aveva vista, etc. e viene fatto un nome, quello di un medico. Ma questo medico non appare nei fascicoli delle altre tre vittime, perché non c'è niente, nessun elemento che le relazioni. Quindi abbiamo questa annotazione da parte dei carabinieri in cui si dicono certi del fatto che quell'uomo fosse il colpevole, ma, visto che nel frattempo era morto, hanno archiviato tutto.

Alla luce di tutti gli elementi emersi fino ad oggi, lei personalmente che idea si è fatta sull'intera vicenda del mostro di Udine?

Quella che ho ripetuto sin dall'inizio. Noi non abbiamo elementi certi e incontrovertibili perché si possa pensare che a Udine esista o che sia esistito un mostro. Io sono dell'idea che ogni vittima abbia il suo mostro, ed è su questo che la Procura ha indagato all'epoca. Io conosco l'investigatore che ha indagato per i primi delitti, e posso dire con estrema tranquillità che devono essere rispedite al mittente, anche con abbastanza sdegno, tutte le accuse relative al fatto "tanto era una prostituta, quindi non è importante. Se fosse stata la figlia di un medico, per esempio, allora lo avreb- bero sicuramente trovato". Assolutamente no. Conosco l'etica e la coscienza dell'investigatore, ma conosco soprattutto la logica con cui venivano fatte le indagini. Se noi andiamo ad aprire un trattato di criminologia, sotto la voce "vittimologia", la prostituta, purtroppo, è la vittima per eccellenza delle indagini svolte con difficoltà, se manca l'apparato tecnico scientifico. Se dovessero trovare il mio cadavere, non servirebbe fare dei giri immensi per riuscire a trovare il colpevole; un familiare, un cliente insoddisfatto o un collega. Per quanto riguarda una prostituta, invece, può trattarsi di chiunque. Suo padre, un cliente occasionale che ha visto una sola volta, un cliente con cui ha litigato perché qualcosa non ha funzionato durante il rapporto, etc. Il nome che tutta Udine vociferava, se fosse arrivato in Procura probabilmente l'esito sarebbe stato diverso. Ma, ribadisco, è il nome per una sola vittima del 1989, niente di più e niente di meno.

E il fatto che l'ultima vittima, esattamente come le tre precedenti, presentasse dei tagli longitudinali sulla zona toracica e addominale?

Potrebbe essere un indizio da cui muoversi, questo sì. Non dico che non significhino nulla, dico soltanto che non abbiamo il DNA della stessa persona su tutti gli omicidi. Non abbiamo uno stesso setting di tutte le vittime; qualcuna è stata strangolata, qualcuna è stata carbonizzata. Oltre il segno presente su alcune vittime, c'è tutto un altro mondo che però non combacia. Ribadisco però, ci potrebbe essere un mostro per quanto riguarda quelle quattro vittime. Non esiste un mostro comune a tutte le vittime di cui comunque stiamo parlando. Anche perché, gli autori di qualche omicidio sono già in carcere. Potrebbe essere uno spunto investigativo, ma soltanto questo, nulla di più.

\section{Elena Commessatti}

Intervista a Elena Commessatti, scrittrice e giornalista. Autrice di tre romanzi relativi alla vicenda del Mostro di Udine: Femmine un giorno, Agata Est e il Mostro di Udine, Agata Est e il mistero delle monete

Le è stata una delle prime persone a interessarsi autonomamente della vicenda del Mostro di Udine. Cosa ha scatenato in lei questa curiosità?

Ho iniziato ad occuparmi della vicenda del Mostro di Udine nel 2008, e la prima sensazione che ho avuto è che si trattasse di una storia dimenticata, o meglio, mai approfondita. Citando un mio articolo: "La cifra dolorosa di questa storia è il tempo, che passa inesorabile, mentre la gente continua a vivere nello stesso modo e con gli stessi rituali, e per queste donne, chiamate "puttane", c'è poco da fare. In città si è mormorato per anni il nome di un sospettato, un medico dalla parte "bene" della società, ma è morto senza un processo, e morto il reo si estingue il reato". ${ }^{10}$ È questo che io ritengo sia successo.

Da narratrice all'inizio volevo raccontare una storia di provincia che avesse a che fare con il pettegolezzo; volevo ricreare l'atmosfera del film del 1965 "Signore e signori" di Pietro Germi, ambientato a Treviso. Il 10 agosto 2008 vado dall'allora comandante del nucleo investigativo dei carabinieri, Fabio Pasquariello;

9 Gianpaolo Tosel, sostituto procuratore a Udine fino al 1985.

10 Commessatti E (2015). Lui, lo chiamarono «mostro di Udine». Loro, erano «femmine della notte». E nessuno indagò. https://27esimaora.corriere.it/19_maggio_15/lui-chiamarono-mostroudine-loro-erano-solo-femmine-notte-nessuno-indago-b8a 7ad22-768c11e9-bcad-cb3963eb9263.shtml 
avevo la necessità che lui mi spiegasse quali erano gli strumenti e i metodi investigativi usati negli anni ' 80 , perché volevo ambientare questo romanzo negli anni della mia gioventù. Davanti al mio progetto, Pasquariello mi ha detto: "Ma lei sa che mi sta riferendo qualcosa che è realmente accaduto?". E poi in quel pomeriggio mi ha raccontato la sua versione. Se ne era occupato appena aveva iniziato a prestare servizio a Udine. E quelle poche ore di conversazione hanno incredibilmente legittimato la mia trama. La fortuna è stata quella che ci fosse il giusto tempo di distanza tra gli avvenimenti e la possibilità di raccontarli. Però è anche vero che nessun giornalista l'aveva fatto prima di me in maniera organica. E la storia, a pensarci bene, era comunque lì, tra i giornali, negli archivi. Nascosta tra le carte. E poi, e poi quando ho iniziato a scriverne, il sospettato numero uno di cui il mio romanzo poi parla era già morto, anche se non avevo accesso ai fascicoli.

Com'è nato il personaggio di Agata Est, protagonista dei suoi libri?

Essendo legata alla narrativa di genere e alla serialità, volevo creare un'investigatrice che si occupasse di cold case nel Nord Est d'Italia. Creo quindi questa collana, che nasce con l'intenzione di attrarre il lettore in una storia dove i personaggi continuano a vivere anche nelle varie puntate. Seriale l'idea e, in questo caso, seriale il killer. Agata Est nasce del tutto volontariamente come un'investigatrice sui generis; non è una poliziotta, è una biografa, si occupa quindi delle vite altrui, e ha una forte sensibilità nell'ascoltare il respiro degli altri, delle persone che le stanno accanto. È molto istintiva, intuitiva; alle spalle ha una famiglia di figure investigative che si sono sempre occupate di questo nella vita: la nonna, la zia. Sono legate a un'investigazione di tipo tradizionale, fatta di pedinamenti, tradimenti, riguardanti attività del quotidiano. Agata è una donna con un intuito molto spiccato; è un insieme di investigatrici che conosco, e che non conosco. Nata per essere diversa. Non ha figli, ha una grande paura della morte e un grande amore per gli oggetti che, a differenza delle persone, non possono tradirla. La sua carta vincente è proprio questa enorme fragilità, che le consente di essere sempre in ascolto. Ci tengo particolarmente a questo aspetto. Agata Est prova pietas per l'assassino. Un uomo solo, disadattato, malato, schizofrenico, non curato adeguatamente. Nel romanzo affronto anche quest'ultimo argomento, legato alla malattia mentale. E per Agata Est, da un lato c'è la parte pop che è il suo vestito, la sua figura di donna bellissima, seducente. Troppo appariscente anche per poter pedinare qualcuno. Dall'altro lato, invece, c'è la figura fragile. È struggente la verità su Agata e anche sulla concezione della vita, e la faccio uscire tra le pagine attraverso il grande rumore che gli oggetti producono, raccontando di Udine, città che amo moltissimo, piena di luce e colori tiepoleschi, eppure permeata dal male. Un male silente e laborioso. Alla fine, ciò che affermo e che ho anche riportato nel mio romanzo: perché in una città di 100mila abitanti, dall'impronta conservatrice, dove le vie legate al mestiere sono ancora le stesse, dove la prostituzione al tempo era pubblica, sulle strade, dove tutti conoscevano tutti, nessuno ha mai visto nulla di fondamentale?

Agata Est è questo: una donna con un grande fiuto e un grande amore per la verità, ma anche con una grande capacità di ascolto della città e delle persone. Sono una grande sostenitrice del metodo investigativo tradizionale; l'umano è la miglior fonte e bisogna saperlo ascoltare, ancora di più della tecnologia e delle indagini scientifiche. Le province sono a misura d'uomo, ci si conosce, ed è questo che mi crea rabbia: pensare che nessuno sappia nulla di utile al fine di interrompere questo flusso di omicidi.

Da scrittrice e giornalista che ancora oggi si occupa della vicenda, in tutti questi anni di ricerche dirette, lei che idea personale si è fatta?

La mia personale idea è che esistano più mostri, non uno sol- tanto. Ovvio; sono tante le tipologie di omicidio. Certo io non so chi sia il mostro di cui parlo nei miei libri. Ma è probabile che ce ne sia uno solo per quattro delitti, forse cinque. Non concordo con chi dice però che questo è un caso giornalistico. Questo è un caso giudiziario, prima di tutto, interessante e stravagante, che porta in luce un'indubbia serialità collegata al modus operandi di un'unica mano, per alcuni delitti. Non c'è nulla di esagerato nel dire questo. Ci tengo a dire che nel tempo sono diventata intima della sofferenza di Fedra Peruch, la figlia di Marina Lepre, e l'aiuterò sempre. È una ragazza coraggiosa, che continua a combattere. Aveva 9 anni quando sua madre è stata uccisa; non la lascerò mai. Lo stesso senso di protezione ce l'ho nei confronti di tutte le altre persone che hanno subito questa ingiustizia; sono famiglie che non riescono a uscire da questo lutto perché ormai sono trascorsi anni senza una risposta. La speranza che ho è che, attraverso il DNA delle nuove prove da analizzare, si riesca a trovare una corrispondenza tra dati investigativi. Al momento, però, questo non è ancora successo. Non posso quindi fare altro che usare la mia penna, e stare al fianco della giustizia. Se poi lei mi chiede se esistano vittime di serie $\mathrm{A}$ o di serie $\mathrm{B}$, rispondo che non c'è una classifica, ma un pregiudizio, questo sì, per le mie "femmine della notte", e che continua ancora nel 2021 ad accomunarle.

\section{Conclusioni}

L'obiettivo che mi sono imposta fin dall'inizio della stesura di questo lavoro di tesi è quello di riportare alla luce un mistero italiano rimasto per troppo tempo nell'ombra. Eppure, avrebbe tutte le caratteristiche adatte per rientrare nella classifica dei peggiori omicidi seriali d'Italia.

Ho voluto fortemente trattare questo argomento innanzitutto perché ha interessato luoghi che io stessa personalmente conosco e frequento. Spinta forse dalla curiosità di saperne di più.

Sicuramente, se tutto questo fosse accaduto ai giorni nostri, avremmo avuto un'attenzione mediatica totalmente diversa, ma soprattutto non parleremmo più di "cold case", ovvero di un mistero non risolto. Molto probabilmente, sarebbe stato possibile arrivare ad un risultato concreto grazie allo sviluppo della tecnologia e degli strumenti investigativi, che hanno reso possibili nuove metodologie di indagine, fondamentali in queste situazioni. Si avrebbe dato una diversa importanza anche a quei seppur pochi elementi reperibili dalle diverse scene del crimine o direttamente dai corpi delle vittime. Nel caso in cui questi elementi non fossero appartenuti allo stesso omicida, allora sarebbero stati fondamentali per riuscire a contattare nuovi individui al fine di ottenere il maggior numero possibile di informazioni utili a ricostruire ciò che accadeva in quelle notti.

Il Mostro di Udine, chiunque esso sia, rientra nella categoria degli assassini seriali; tre o più vittime, in luoghi e momenti diversi. Al giorno d'oggi è piuttosto raro parlare di serial killer. Grazie allo sviluppo degli strumenti investigativi ci è permesso arrivare a un risultato molto prima che il soggetto riesca a compiere una serialità di delitti; nella maggioranza dei casi, infatti, viene incastrato e fermato già dopo il primo reato. Il problema, all'epoca, fu che la mancanza di prove certe date da una carenza nei mezzi e strumenti investigativi creò, nelle varie personalità implicate nel processo di indagine, diverse teorie, nessuna delle quali sarebbe stata valida per mancanza di prove reali. È anche importante sottolineare che le vittime erano delle prostitute e donne ai margini, e, all'interno di questo mondo, era ed è tutt'oggi complicato ottenere delle informazioni. Chi conosce o sa qualcosa, non parla per paura di essere conseguentemente etichettato. Le vittime, a causa di que- 
sto lavoro, venivano continuamente in contatto con nuove persone; impossibile sarebbe quindi stabilire quale di loro fosse l'assassino. Potrebbe essere chiunque, o nessuno.

Ho scelto di prendere in considerazioni diversi punti di vista, di persone che sono state tutte, a loro modo, implicate nel caso del Mostro di Udine. Personalità che hanno vissuto sulla loro pelle la vicenda, e che, negli anni, si sono fatte una loro idea di quanto accaduto. Esperienze, visioni ed idee diverse; alcune delle quali non convinte del fatto che dietro a quei quattordici omicidi, ci fosse la stessa mano.

La giurisprudenza insegna il principio de "l'oltre ogni ragionevole dubbio", che cioè non è possibile emettere una sentenza di condanna nei confronti di un individuo se non in presenza di prove schiaccianti della sua colpevolezza.

Per quanto riguarda la figura dell'unico sospettato, credo sia necessario prenderne le distanze e valutare tutto nel modo più oggettivo possibile. È vero che è decisamente probabile che l'omicida faccia ritorno sulla scena del delitto, ma la presenza dell'uomo sul luogo del ritrovamento dell'ultimo cadavere potrebbe essere semplicemente dovuta ad una grande coincidenza. Ammesso e concesso che fosse stato davvero lui l'assassino, non sarebbe stato possibile collocarlo in nessun'altra scena del crimine, se non quella di Marina Lepre.

L'obiettivo di questa tesi è quindi quello di parlare, di parlarne, perché solo parlando le cose rimangono in vita. Restare fermi e lasciarsi scivolare le cose di dosso, a volte come in questo caso specifico, diventa pericoloso. È fondamentale ricordare che le vittime erano donne, mogli, mamme, sorelle, figlie e che chi rimane ha il diritto di pretendere giustizia e comprendere che cosa sia realmente accaduto.

\section{Blibliografia}

Burello L (2015). Dannato Friuli. Storie di antichi omicidi per il dopocena. Udine, Gaspari Editore.

Commessatti E (2019). Agata Est e il Mistero delle monete. Udine: Gaspari Editore.

Commessatti E (2020). Agata Est e il Mostro di Udine. Udine: Gaspari Editore.

Commessatti E (2015). Femmine un giorno. Udine: Bébert Edizioni.

Pizzichi A (2021). Disturbed: Le folli storie dei serial killer più perversi dei tempi moderni. Milano: Auralcrave Libri.

De Luca R (1995). Mostri d'Italia e serial killers. Detective \& Crime.

De Luca R (2001). Anatomia del serial killer 2000. Nuove prospettive di studio e intervento per un'analisi psico-socio-criminologica dell'omicidio seriale nel terzo millennio. Roma: Giuffrè Editore.

De Luca R, Bruzzone R (2013). Anatomia del crimine in Italia. Roma: Giuffrè Editore.

Douglas JE (2006). Crime classification manual: a standard system for investigating and classifying violent crimes. San Francisco: Jossey-Bass Inc Pub.

Kelleher MD (1999). Murder most rare: The female serial killer. New York, Bantam Doubleday Dell Publishing Group Inc.

Lucarelli C, Picozzi M (2003). Serial killer. Storie di ossessione omicida. Milano: Mondadori Editore.

Mastronardi VM (2001). Manuale per operatori criminologici e psicopatologi forensi. Milano, Giuffrè Editore.

Mastronardi VM, De Luca R (2013). I Serial Killer. Il volto segreto degli assassini seriali: chi sono e che cosa pensano? Come e perché uccidono? La riabilitazione è possibile? Roma: Newton Compton Editori.

Nuzzi G, Commessatti E (2021). Dal DNA del mostro di Udine riparte la caccia a "Ignoto 1". Settimanale Italiano Lo Specchio, 21 febbraio 2021.

Picozzi M (2008). Crime Classification Manual. Il manuale dell'FBI sulla classificazione e investigazione dei crimini violenti. Torino: Centro Scientifico Editore.

Quotidiano Il Friuli.

Quotidiano Il Messaggero Veneto.

Quotidiano La Repubblica.

Schechter H (2003). Furia omicida. Viaggio nel mondo dei serial killer. Milano: RCS Libri.

Studio Legale Tosel, Udine. Fascicolo di richiesta riapertura indagini.

\section{Sitografia}

Corriere.it. Il mostro di Udine, 30 anni fa l'ultimo omicidio del serial killer misterioso. Riaperte le indagini: reperti al Ris - Consultato il 28.08.2021. https://www.corriere.it/cronache/cards/mostroudine-30-anni-fa-1-ultimo-omicidio-serial-killer-misterioso/inuovi-reperti.shtml

Armi bianche. Definizione "arma bianca", consultato il 24 settembre 2021. https://armi-bianche.blogspot.com/2013/04/definizionearma-bianca.html

TGR Friuli Venezia Giulia. Chiesta la riapertura delle indagini sul Mostro di Udine, consultato il 15.06.2019. https://www.rainews.it/tgr/fvg/articoli/2019/03/fvg-mostro-udine-omicidiprostitute-indagini-442559fc-814f-4944-ace8-f2c836eec 955.html

Ilsussidiario.net. Chi è il serial killer di donne: i sospetti sul vecchio chirurgo, consultabile su MOSTRO DI UDINE/ Chi è il serial killer di donne: i sospetti sul vecchio chirurgo..., consultato il 15.06.2019https://www.ilsussidiario.net/news/cronaca/mostrodi-udine-serial-killer-di-donne-fragili-i-sospetti-sul-vecchiochirurgo/1885260/

Il Messaggero Veneto. Ecco il profilo del "Mostro di Udine". Consultato il 12.07.2021. https://necrologie.messaggeroveneto.gelocal.it/news/34341

Corriere.it. Lui, lo chiamarono «mostro di Udine». Loro, erano «femmine della notte». E nessuno indagò. Consultato il 29.10.2021. https://27esimaora.corriere.it/19_maggio_15/luichiamarono-mostro-udine-loro-erano-solo-femmine-notte-nessuno-indago-b8a7ad22-768c-11e9-bcad-cb3963eb9263.shtml

Ilsussidiario.net. Marina Lepre, chi è? Uccisa per errore dal Mostro di Udine? Consultato il 15.06.2019. https://www.ilsussidiario. net/news/cinema-televisione-e-media/marina-lepre-chi-e-uccisa-per-errore-dal-mostro-di-udine/1885071/

Regione.fvg.it. Giustizia e Criminalità nel Friuli-Venezia Giulia. Consultato il 28.07.2021. https://www.regione.fvg.it/rafvg/ export/sites/default/RAFVG/GEN/statistica/FOGLIA61/allegati/Giustizia e criminalitx luglio 2010.pdf

Cinematographe.it. Il mostro di Udine: su Crime+Investigation la serie dedicata a casi irrisolti. Consultato il 25.07.2021. https://www.cinematographe.it/tv/il-mostro-di-udine-crimeinvestigation-casi-irrisolti/

polizia-penitenziaria.it. Le Due Città, raccontare il carcere. Consultato il 21.08.2021. https://www.polizia-penitenziaria.it/ index.php/archivio/533-archivio/2008/aprile-2008/1343-ilprofilo-del-killer-1343

Friulioggi.it. "L'identità del Mostro ad un passo dall'essere rivela- 
ta". Le tracce trovate nel Dna. Consultato il 18.08.2021. https://www.friulioggi.it/primo-piano-2/identita-mostroudine-tracce-dna-12-agosto-2021/

Ancaf.it. Il Mostro di Udine. Un "cold case" ancora irrisolto. Consultato il 18.08.2021. https://www.ancaf.it/2021/07/16/i1mostro-di-udine-un-cold-case-ancora-irrisolto/

Corrieredelmattino.it. Operazione mistero: il Mostro di Udine. Consultato il 11.10.2021. https://corrieredelmattino.it/contents/ operazione-mistero-il-mostro-di-udine

marilenacremaschini.it. Definizione e categorie dei serial killer. Consultato il 28.08.2021. https://www.marilenacremaschini. it/chi-sono-i-serial-killer/

Mastronardi VM, Delli Compagni E (2004). Stragi Familiari: i Family Mass Murder (Le Statistiche). Rassegna di Psicoterapie, Ipnosi, Medicina Psicosomatica, Psicopatologia Forense. Consultato il 06 giugno 2021. http://www.masterscienzecriminologiche.it/rivista/Rivista_9_N_1_Gennaio_Aprile_2004.pdf

Ilsussidiario.net. Irene Belletti, chi è la prima vittima del Mostro di Udine? Consultato il 15.06. 2021. https://www.ilsussidiario.net/ news/cinema-televisione-e-media/irene-belletti-chi-e-e-stata-laprima-vittima-del-mostro-di-udine/1885452/

Il Messaggero Veneto. Mostro di Udine, parla la figlia di una vittima.
Consultato il 18.09.2021. https://necrologie.messaggeroveneto.gelocal.it/news/85539

Cronaca-Nera.it. Ramon Berloso, il killer della balestra .Consultato il 14.10.2021. http://www.cronaca-nera.it/1708/ramon-berlosokiller-balestra

Biografieonline.it. Theodore Kaczynski. Consultato il 23.10.2021. https://biografieonline.it/biografia-theodore-kaczynski

Espresso.repubblica.it. Il mostro di Udine. Consultato il 23.06.2021. https://espresso.repubblica.it/foto/2012/01/18/galleria/ilmostro-di-udine-1.81938

\section{Video}

Lena M, Agostini F (2019). Documentario "Il Mostro di Udine". Disponibile su www.sky.it, canale CrimeInvestigation.

Nero Crime (2016). Il Mostro Di Udine. Consultato il 3.09.2021. https://www.youtube.com/watch?v=y9AdG_yjouQ

Border Nights (2019). Puntata 315, PODCAST e PLAYLIST (Edi Sanson, Patrizia Broghammer 04-06-2019). Consultato il 23.08. 2021. http://www.bordernights.it/edi-sanson-broghammer/

Key words: cold cases; serial killer; Udine.

Parole chiave: casi irrisolti; serial killer; Udine.

Palabras clave: casos sin resolver; asesino en serie; Udine.

Received for publication: 1 September 2021.

Accepted for publication: 5 October 2021.

This article is distributed under the terms of the Creative Commons Attribution Noncommercial License (by-nc 4.0) which permits any noncommercial use, distribution, and reproduction in any medium, provided the original author(s) and source are credited.

${ }^{\circ}$ Copyright: the Author(s), 2021

Licensee PAGEPress, Italy

Rivista di Psicopatologia Forense, Medicina Legale, Criminologia 2021; 26:633

doi:10.4081/psyco.2021.633 